\title{
Dialética do progresso e do domínio da natureza: técnica em Theodor W. Adorno e José Ortega y Gasset ${ }^{1}$
}

\author{
Jaison José Bassani * Alexandre Fernandez Vaz * * \\ http://dx.doi.org/10.1590/0103-7307201407511
}

\section{Resumo}

0 artigo apresenta resultados de um estudo comparativo sobre aspectos da questão da técnica em obras de Theodor W. Adorno e José Ortega y Gasset, desdobrado em suas relações com o progresso, o domínio da natureza e a cultura de massas. Pretende com isso encontrar o tema da formação e seus impasses, problematizando-o mais uma vez. 0 cotejamento parte de comentário de Adorno sobre Ortega, segundo o qual este seria um crítico conservador da cultura, para então confrontar teoricamente os temas escolhidos. A análise da técnica em Adorno e em Ortega dá-se a partir da posição que cada um apresenta nos termos da condição humana, extraindo-se daí as consequências analíticas, mas também formativas, de cada autor: uma vinculada à perspectiva de que seria a técnica motor da existência e produção do supérfluo; outra, que a compreende no interior de uma dialética do esclarecimento.

\section{Palavras-chave}

Formação, Theodor W. Adorno, José Ortega y Gasset, domínio da natureza, dialética do progresso.
* Universidade Federal de Santa Catarina (DEF/CDS Campus Universitário Reitor João David Ferreira Lima - Trindade), Florianópolis, SC, Brasil. jaisonbassani@uol.com.br

** Universidade Federal de Santa Catarina (PPGE/PPGICH - Campus Universitário Reitor João David Ferreira Lima - Trindade), Florianópolis, SC, Brasil. alexfvaz@uol.com.br

1. 0 trabalho tem origem na tese de Doutorado em Educação de Jaison José Bassani, Corpo, educação e reificação: Theodor W. Adorno e a crítica da cultura e da técnica, defendida no PPGE/UFSC em 2008. Os autores agradecem à CAPES, à FAPESC, ao DAAD e ao CNPq pelas bolsas recebidas, bem como ao CNPq pelo extenso apoio ao Programa de Pesquisas Teoria Crítica, Racionalidades e Educação (IV), do qual este trabalho é também resultado. 


\title{
Dialectic of progress and of domination of nature: technique in Theodor W. Adorno and José Ortega Y Gasset
}

\begin{abstract}
The article presents results of a comparative study on how the question of technique is approached in the works of Theodor W. Adorno and José Ortega y Gasset. It looks into how this question is unfolded in relation with the notions of progress, domination of nature and mass culture. The intention is to question the theme of formation (Bildung) and its impasses in these works. The discussion starts with the analysis of Adorno's view of Ortega as a conservative critic of culture, and is followed by a theoretically confrontation between both thinkers. The analysis of the notion of technique by Adorno and Ortega takes into account the views that each one held on the human condition, extracting their analytical and formative consequences: for the first author, technique is seen as the engine of existence and of superfluous production while for the second one technique should be apprehended within a dialectic of enlightenment.
\end{abstract}

Keywords

Formation, Adorno, Theodor W., Ortega y Gasset, José, domination of nature; dialectic of progress. 


\section{Introdução}

Uma parte significativa das críticas de Theodor W. Adorno (1903-1969) ao progresso e à racionalidade instrumental, eixo fundamental de sua obra e que encontra no tema da técnica uma importante síntese, está vinculada ao debate e ao confronto, nem sempre de maneira explícita, com outras tradições que também se debruçaram sobre a temática. Esse é o caso daqueles autores que figuram alinhados, no registro da Teoria Crítica, sob a genérica rubrica de críticos conservadores da civilização e da cultura, especialmente Oswald Spengler, Thorstein Veblen e Aldous Huxley, cujas obras mereceram estudos específicos por parte de Adorno. ${ }^{2}$ Outro autor desse mesmo contexto e que teve sua obra criticada pelo frankfurtiano, ainda que de forma mais discreta e esparsa, é o filósofo espanhol José Ortega y Gasset (1883-1955).

Ortega foi um dos primeiros filósofos contemporâneos, ainda no terço inicial do século XX, a ocupar-se da técnica como problema filosófico. Apesar de não ser possível falar de uma filosofia da tecnologia em sua obra - considerando-se a reduzida dimensão do corpus sobre o assunto -, a temática adquire centralidade em suas reflexões sobre o tempo que lhe coube viver.

Além da preocupação com a origem e o significado antropológico da técnica, presente em Meditación de la técnica, de 1939, e na famosa conferência El mito del hombre allende la técnica (Ortega y Gasset, 1997, p. 99-108; Ortega y Gasset, 1983f, p. 617-624), proferida ante Martin Heidegger e os mais importantes arquitetos da Alemanha em 1951, no Colóquio de Darmstadt, Ortega também empreendeu esforços, ainda que em menor escala, para compreender a crescente importância social do desenvolvimento tecnológico no começo do século XX e a forma como ele teria condicionado a vida do homem naquele momento histórico. Esses esforços se evidenciam em sua obra mais famosa, La rebelión de las masas (Ortega y Gasset, 1983d, p. 111-310; 2002), publicada em 1930, na qual o tema alcança relevância, na medida em que a técnica, ao ter elevado o nível de vida do europeu médio a um patamar que nunca antes havia sido visto na história da humanidade, aliviando sobremaneira as agruras de sua existência, teria proporcionado, exatamente por causa dessa subida no nível vital e da superabundância de mercadorias disponibilizadas, a aparição do homem-massa.

As referências aos trabalhos de Ortega y Gasset na obra de Adorno estão circunscritas a um conjunto não muito extenso de passagens nas

2. Referimo-nos especificamente aos seguintes ensaios: sobre Spengler (Adorno, 1986a, p. 47-71; 2001, p. 43-67; 1986f, p. 140-148 e p. 197-199); sobre Veblen (Adorno, 1986a , p. 72-96; 2001, p. 69-90); sobre Huxley (Adorno, 1986a, p. 97-122; 2001, p. 91-116). 
quais o frankfurtiano tece, en passant, considerações de caráter abrangente sobre a obra do madrileno. ${ }^{3}$ Este é o caso daquela que é provavelmente a mais conhecida referência a Ortega, presente nas primeiras páginas do prefácio de Dialética do esclarecimento (Horkheimer; Adorno, 1985; 1986). Ao lado de Jaspers e Huxley, Ortega é caracterizado como um crítico da civilização cuja análise da cultura e seus destinos se mostraria hipostasiada e regressiva, como se esta tivesse valor por si mesma. Não seria o caso de “mover para trás a roda da História” (Horkheimer, 2000, p. 164). Nas palavras de Horkheimer e Adorno (1986, p. 15; 1985, p. 15):

o que está em questão [em Dialética do esclarecimento] não é a cultura como valor, como pensam os críticos da civilização Huxley, Jaspers, Ortega y Gasset e outros. A questão é que o esclarecimento tem que tomar consciência de si mesmo, se os homens não devem ser completamente traídos. Não é da conservação do passado, mas de resgatar a esperança passada que se trata.

Embora o debate entre eles não tenha sido estreito, talvez pudéssemos dizer, se considerarmos o espírito que anima Adorno à discussão da obra de autores contemporâneos, que Ortega está, negativamente, muito mais presente na obra do frankfurtiano do que indicam as referências diretas a seus trabalhos. Esse "espírito", movimento de Dialética do esclarecimento, pode ser sintetizado pela supracitada passagem do prefácio, na qual são citados, não fortuitamente, Huxley, Jaspers e Ortega y Gasset. De maneira geral, e a despeito das diferenças teóricas que certamente há entre autores como Huxley, Spengler e Veblen (Adorno, 2001), pode-se dizer que Adorno via no olhar crítico sobre a sociedade contemporânea um apego, às vezes explicitamente declarado, a um passado havia muito superado ou ainda àquilo que haveriam projetado idealmente nesse mesmo passado. Desse tipo de crítica buscavam Adorno e os demais membros do Instituto de Pesquisa Social afastar-se, pois ela confrontava os aspectos negativos do cientificismo, da mecanização e da cultura de massas, enfatizando "velhos ideais" ou indicando "novos objetivos a serem alcança-

3. Referências diretas à obra de Ortega y Gasset podem ser encontradas, por exemplo, nas seguintes passagens: Horkheimer e Adorno (1986, p. 15; 1985, p. 15), Adorno (1986a, p. 35; 2001, p. 31; 1986e, p. 593-594; 1986f, p. 1718 e p. 221-227). dos sem o risco da revolução" (Horkheimer, 2000, p. 164-165). Ela utilizava a terminologia da crítica social, mas retirava, ao mesmo tempo, o seu ferrão, ou seja, o elemento transformador e, por isso, 
mostrar-se-ia ainda mais complacente com o mundo tal como era (Adorno, 1986a, p. 32; 2001, p. 28).

Ortega, por sua vez, não fez, nos textos presentes nos 12 volumes de suas Obras completas (Ortega y Gasset, 1983a), qualquer referência a Adorno ou a outro integrante do Instituto de Pesquisa Social, embrião da Escola de Frankfurt. Se, de alguma forma, a barreira linguística limitou o contato de Adorno com os escritos de Ortega embora já houvesse, na época, várias traduções de seus livros para o alemão e o inglês ${ }^{4}$-, esse certamente não constituía um fator de limitação no caso do filósofo espanhol, que havia residido e estudado durante vários anos na Alemanha. Ortega destinava um profundo interesse não apenas à cultura, mas também à filosofia germânica, como atestam as inúmeras referências a Hegel, Herder, Kant, Spengler, Schelling, Goethe, Fichte, Hebbel, entre tantos outros.

Ao propormos uma leitura comparada da questão da técnica - para empregar expressão de Heidegger - em Adorno e Ortega y Gasset, buscamos destacar, especialmente, esse embate materializado nos temas do domínio da natureza, do progresso e da cultura de massas, tópicas caras a ambos os autores, para então encontrar o tema da formação (Bildung) e algo de seus impasses. Se a afinidade temática entre ambos não é de natureza teórico-metodológica, o exercício de cotejamento pode ajudar, no entanto, a melhor compreender os impasses da questão no debate filosófico sobre os destinos da formação e, em linhas mais gerais, seu lugar na interpretação da condição humana.

\section{Um mesmo tema em duas abordagens}

A leitura cotejada das análises que Adorno (em parceria ou não com Horkheimer) e Ortega y Gasset fazem da técnica revela, em um primeiro movimento, pontos de aproximação. Para ambos, embora por diferentes motivos, os eventos históricos que marcaram a primeira metade do século XX fizeram soar um sinal de alerta para a humanidade. As incríveis potencialidades que a técnica poderia facultar acabaram se convertendo, segundo Adorno, não à emancipação e à liberdade, mas à opressão e à escravidão; para Ortega, não ao
4. Citamos dois exemplos. 0 primeiro refere-se à edição alemã de La rebelión de las masas, datada de 1950, citada nos Soziologische Exkurse, manual de introdução à Sociologia, publicado em 1956, elaborado por membros do Instituto de Pesquisa Social e coordenado por seus dois líderes (Institut für Sozialforschung, 1968). No entanto, a primeira tradução para o alemão do famoso livro de Ortega y Gasset, publicada pela Deutsche Verlags-Anstalt, é de 1932, ou seja, dois anos após a publicação em espanhol. Também é de 1932 a versão em inglês citada no capítulo "Sobre o conceito de filosofia", de Eclipse da razão (Horkheimer, 2000), livro que resultou de um conjunto de conferências pronunciadas por Horkheimer na Columbia University, nos Estados Unidos, durante 0 ano de 1944 (0 livro foi publicado em 1946). É importante mencionar este fato porque essas conferências "foram projetadas para apresentar alguns aspectos de uma ampla teoria filosófica desenvolvida pelo autor [Horkheimer] nos últimos anos, em associação com Theodor W. Adorno" (Horkheimer, 2000, p. 10). 
afastamento do que seria puramente natural, em direção à felicidade e ao bem-estar, mas à perda dos desejos e aspirações mais radicalmente humanos. Enquanto Adorno entendia que a técnica havia adquirido, na sociedade moderna, estrutura e posição singularmente fetichizada (Adorno, 1986b, p. 686; 2000, p. 132) e incongruente com as necessidades humanas, Ortega observava que a reconstrução do mundo pelas atividades científicas e técnicas, condição sine qua non para que o homem pudesse habitá-lo, resultara em uma situação paradoxal, em que a abundância de meios determinava a ação no mundo, e não mais o contrário, já que à autocriação técnica do homem não precedia mais nenhum projeto substancialmente vital.

A um segundo ponto de aproximação se chega pela ponderação de certa interpretação, tornada "canônica” e, em certa medida, vulgarizada, que atribui ao "pessimismo" de Adorno uma visão “demonizante” da técnica. Ao otimismo orteguiano, por outro lado, corresponderia uma postura exclusivamente celebrativa do progresso tecnológico. Como se pode ler, ao longo tanto de Meditación de la técnica (Ortega y Gasset, 1997) quanto de La rebelión de las masas (Ortega y Gasset, 1983d, p. 111310; 2002), a atitude de Ortega diante da técnica frequentemente não é afirmativa, revelando, ademais, certo reformismo, ainda que um tanto conservador. No mesmo contexto, a radicalidade das críticas de Adorno à técnica nem sempre é "destrutiva”, pois não a considera exclusivamente como produtora de mazelas ou como uma das causas do fracasso do projeto de emancipação ${ }^{6}$ da Aufklärung.

Em ambos os casos, e esse constitui um terceiro momento de proximidade, as críticas dirigidas ao senhorio da técnica na sociedade contemporânea parecem reivindicar, particularmente diante da inconsciência dos “novos" agentes sociais - os

5. 0 caráter fetichista da técnica advém de que, na relação contemporânea com ela, haveria algo de superlativo e irracional, configurando-se em véu tecnológico (technologischer Schleier): "os homens inclinam-se a considerar a técnica como sendo algo que se restringe a si, um fim em si mesmo, uma força essencial e independente e com isso se esquecem que ela é o braço prolongado dos Homens" (Adorno, 1986b, p. 686; 2000, p. 132).

6. Antes que pela simples condenação peremptória, Adorno se guia pela força contraditória que a técnica, como expressão iluminista, deixa conhecer sobre a sociedade contemporânea: "[...] da funda até a bomba atômica, o progresso é escárnio satânico, mas que, somente na época da bomba atômica, é possível vislumbrar uma situação em que desaparecesse a violência do todo" (Adorno, 1986b, p. 629; 1995, p. 52). homens-massa (Ortega) - ou da perversão da práxis convertida em autoconservação (Adorno), uma inflexão em direção à teoria, especialmente à atividade filosófica, como uma aposta - mas nada além disso - de contraposição ao existente. Os exemplos mais evidentes desse primado reivindicado para a Filosofia, que não significa uma hipóstase ou um superdimensionamento de seu papel, surgem nos dois livros que podem ser tomados como testamento filosófico de cada um dos autores: ¿Qué es filosofía?, de Ortega y Gasset 
(1983e), e Negative Dialektik, de Adorno (1986d). Enquanto o segundo afirma que a filosofia permanece viva porque o momento de sua realização não foi concretizado e que o pensamento, apesar dos protestos dos técnicos e dos executivos do capitalismo monopolista, segue sendo potencialmente instância crítica de uma práxis que se engessa indefinidamente (Adorno, 1986d, p. 15; 2009, p. 11), o primeiro, ao distinguir entre problemas práticos (técnica) e problemas teóricos (filosofia), destaca que, com o cultivo suficiente da filosofia, talvez fosse possível dominar os desvios produzidos pelo tecnicismo: "Si [...] el problema práctico consiste en hacer que sea lo que no es - pero conviene -, el problema teórico consiste en hacer que no sea lo que es - y que por ser tal irrita al intelecto con su insuficiencia" (Ortega y Gasset, 1983e, p. 323).

As diferenças entre um e outro radicam-se tanto no ponto de partida que eles adotam para deslindar os problemas relativos à gênese da técnica e seu percurso de desenvolvimento quanto na forma como encaram as questões mais prementes do momento histórico em que vivem: a ascensão do homem-massa (Ortega) e a recaída da humanidade na barbárie (Adorno). É importante destacar que esses "dois" momentos não são estanques, e só faz sentido separá-los para fins explicativos. 0 movimento que tanto Adorno quanto Ortega fazem, de buscar em uma proto-história da humanidade os elementos para responder aos pontos nevrálgicos colocados pela contemporânea civilização tecnológica, indica a profunda relação, em ambos, entre bases antropológicas e crítica ao presente.

O impulso primevo da racionalidade instrumental, presença magníloqua da imemorial (mas não anistórica) relação de dominação do homem sobre a natureza, na qual a técnica exerce papel fundamental, é procurado por Adorno nos primórdios da civilização ocidental. 0 mesmo ocorre com Ortega, que busca na relação desde sempre presente do homem com a natureza e com o ambiente que o rodeia, ou, nos seus termos, com a "circunstância", 7 respostas às perguntas: "o que é a técnica?” e “por que o homem é um ser técnico?”.

De acordo com a interpretação orteguiana, o empenho do homem não é para sobreviver, para meramente estar no mundo, senão para estar bem no mundo. Seu esforço não é apenas para viver, mas para viver bem (Ortega y Gasset, 1997, p. 43). Só é necessário aquilo que possa tornar possível o bem-estar do homem:

7. Ao livro Meditaciones del Quijote (Ortega y Gasset, 1983b, p. 309-400) pertence uma das mais conhecidas passagens da obra de Ortega: "Este factor de realidad circunstante forma la otra mitad de mi persona: sólo al través de él puedo integrarme y ser plenamente yo mismo. La ciencia biológica más reciente estudia el organismo vivo como una unidad compuesta del cuerpo y su medio particular: de modo que el proceso vital no consiste sólo en una adaptación del cuerpo a su medio, sino también en la adaptación del medio a su cuerpo. [...] Yo soy yo y mi circunstancia, y si no la salvo a ella no me salvo yo." (Ortega y Gasset, 1983b, p. 322, grifos nossos). 
por tanto, para el hombre sólo es necesario lo objetivamente superfluo. [...] Las necesidades biológicamente objetivas no son, por sí, necesidades para él. [...] Sólo se convierten en necesidades cuando aparecen como condiciones del "estar en el mundo", que, a su vez, sólo es necesario en forma subjetiva; a saber, porque hace posible el "bienestar en el mundo" y la superfluidad. De donde resulta que hasta lo que es objetivamente necesario sólo lo es para el hombre cuando es referido a la superfluidad. No tiene duda: el hombre es un animal para el cual sólo lo superfluo es necesario. (0rtega y Gasset, 1997, p. 34-35, grifos nossos).

Elemento determinante no processo de humanização, a técnica é o que permitiria o escape das imposições de uma vida natural, presa estritamente à satisfação de carências materiais. Ela aparece em Ortega, então, como produtora daquilo que é supérfluo, de tudo quanto incrementa o bem-estar, como "esfuerzo para ahorrar el esfuerzo o, dicho en otra forma, es lo que hacemos para evitar por completo, o en parte, los quehaceres que la circunstancia primariamente nos impone" (Ortega y Gasset, 1997, p. 42).

Desse modo, o humano pode dedicar o esforço economizado a quefazeres não biológicos, ocupando-se com a dimensão da vida que, na opinião de Ortega, mais interessa: aquela especificamente humana, de caráter extranatural (Ortega y Gasset, 1997, p. 53), que transcende a natureza e que está por ser feita, que é ainda mera possibilidade de vir a ser (Ortega y Gasset, 1997, p. 48). O homem, para Ortega, é uma espécie de centauro ontológico, na medida em que possui a estranha condição de que seu ser é apenas em parte afim com a natureza. Ele é, a um só tempo, assim como a figura mítica, parte natural - porção que está imersa na natureza e que se realiza por si mesma -, parte extranatural. Essa porção que transcende a natureza não Ihe é dada, realizada; consiste, antes, numa mera pretensão de ser, em um projeto ou programa de vida (Ortega y Gasset, 1997, p. 46-47).

A autofabricação do homem, como argumenta Ortega, tem, no domínio da natureza e da rede de facilidades e dificuldades que constitui a circunstância, seu pressuposto fundamental. Não apenas a justificativa, senão que também a legitimidade da exploração da natureza é oferecida pela ontologia orteguiana, na medida em que a vida humana somente seria possível a partir da cisão ancestral, a ser constantemente atualizada e expandida, com o que seria natural. Apenas no vácuo, no espaço des- 
se distanciamento, é que pode a planta homem florescer. A técnica, nesse quadro, representa a reação enérgica e violenta, um "plano de ataque" ou de "campanha" (Ortega y Gasset, 1983e, p. 86) do humano contra a natureza. ${ }^{8}$ Seria economia de esforço e folga em relação à satisfação das necessidades elementares, a possibilidade de criação, de fabricação de uma sobrenatureza, mundo artificial capaz de garantir a inserção da dimensão extranatural do homem.

Para Adorno, a relação entre técnica e natureza se dá numa perspectiva diferente da de Ortega e está diretamente vinculada à crítica que, conjuntamente com Horkheimer, empreende ao processo, em grande medida unilateral, pelo qual a Aufklärung foi conduzida na história da humanidade. A técnica representa para eles a culminação histórica de um modelo de racionalidade que se instaurou a partir de uma atividade dominadora da natureza.

De modo semelhante ao filósofo espanhol, Adorno reconhece que, sem distanciamento e algum controle sobre a natureza, não seria possível haver razão e subjetividade. Observa algo, no entanto, que escapa a Ortega: que esse movimento de afastamento se dá de maneira violenta e não refletida, e que o alheamento da natureza com fins de domínio e operacionalização acaba retroagindo sobre o próprio humano, na medida em que este é parte daquela. Esse processo de domínio não é, portanto, isento de dor e sofrimento, porque, na qualidade de objeto rebaixado à mera naturalidade, o humano está submetido à mesma tirania com que subjuga a natureza.

O foco de Ortega, no entanto, não reside na parte "animalesca”, que estaria imersa na natureza e se realizaria por si. Sua atenção se dirige para aquela porção que é mera pretensão de ser. Se a técnica deve, como força criadora externa a serviço do projeto vital do homem, amplificar a rede de facilidades e superar a de dificuldades, impostas pela natureza (ou, em outros termos, também orteguianos, pela "circunstância"), parece não haver problemas no fato de ela retroagir de forma enérgica - tal como defende que seja em relação à natureza externa - sobre o corpo do homem. 0 próprio Ortega confirma essa possibilidade, quando diz que o conceito de "circunstância" não está restrito apenas à paisagem que nos rodeia e na qual estamos inseridos, mas pode ser estendido, sem maiores problemas, ao corpo e à alma (Ortega y Gasset, 1997, p. 49).

Outra diferença bastante significativa que emerge da leitura comparada de Ortega e Adorno, como sugere Rubio (1999), se mostra em torno de

8. "En vez de vivir", diz Ortega (Ortega y Gasset, 1997, p. 53, grifos nossos), "al azar y derrochar su esfuerzo, necesita este [o homem] actuar conforme a un plan para obtener seguridad en su choque con las exigencias naturales $y$ dominarlas con un máximo de rendimiento". 
duas figuras que representariam, metaforicamente, os mediadores da relação entre técnica e natureza. No caso de Ortega, o “operador” da técnica seria o homo faber, aquele que toma, de modo algo ambíguo, a natureza não propriamente como inimiga, mas como substrato de onde se cria a vida pelo seu aperfeiçoamento, pelo movimento de qualificá-la pela técnica. O homem é, como afirma Ortega, “homo sapiens porque es, quiera o no, homo faber, y la verdad, la teoría, el saber no es sino un producto técnico" (Ortega y Gasset, 1983e, p. 85). "Por eso”, diz o autor em outra passagem, "el título más claro de nuestra especie es ser homo faber” (Ortega y Gasset, 1983d, p. 288).

Para Adorno (e Horkheimer), por outro lado, nas raias de um esclarecimento que abriu mão da exigência de pensar a si próprio, a relação que se estabelece com a natureza está baseada unicamente em princípios de cálculo e utilidade, de forma que o sujeito do conhecimento, o homo sapiens, “operador” da técnica e dos procedimentos científicos, teria um ímpeto muito mais destruidor e repressivo:

o esclarecimento comporta-se com as coisas como o ditador se comporta com os homens. Este os conhece na medida em que pode manipulá-los. 0 homem da ciência conhece as coisas na medida em que pode fazê-las. [...] e a essência das coisas revela-se como sempre a mesma, como substrato da dominação. (Horkeimer; Adorno, 1985, p. 24; 1986, p. 25).

A técnica aparece em Ortega não apenas sob uma lógica utilitarista, uma vez que ela não é apenas remédio contra o medo e a angústia - decorrentes do fato de o humano viver "desorientado" em sua radical inadaptabilidade -, mas também, e quiçá sobretudo, produtora daquilo que é supérfluo, de tudo quanto incrementa o bem-estar, e não apenas o estar. Trata-se da dimensão "luxuosa e esportiva da vida" (Ortega y Gasset, 1983c, p. 609-610; 1983e, p. 348). Essa dimensão, em seu íntimo afã de felicidade, é uma espécie de núcleo gerador não apenas do agir técnico, na medida em que o coloca a serviço da dignidade da vida, mas de toda a empresa humana, o que inclui a cultura, os jogos, a sociedade, a política, o pensamento e a forma mais expressiva deste, a filosofia. Todas as grandes ações do homem derivam, por decantação posterior, do caráter lúdico-expressivo da vida humana. A técnica auxilia na tarefa de viver, de cumprir e executar o projeto extranatural do humano, mas ela, afirma Ortega, não o define. Ela estaria a serviço da expansão da vitalidade humana, não no sentido de vida biológica, mas de unidade interna da qual partem todas as 
formas exteriores, como especificações, particularizações, concreções desse "ímpeto originário" (Ortega y Gasset, 1983c, p. 272-306; Ortega y Gasset, 1997, p. 53-54). A técnica, que não é única e imutável na história da humanidade, mas uma invenção vinculada aos diferentes projetos que o homem idealizou e realizou concretamente (Ortega y Gasset, 1997, p. 63-66), seria uma espécie de derivação ou face externa de uma capacidade inventiva interior, mais original e, portanto, de caráter pré-técnico. Essa seria a invenção humana por excelência, denominada por Ortega de "desejo original" (Ortega y Gasset, 1997, p. 54).9

Para Adorno, no entanto, todas as produções humanas carregam consigo a mácula da violência constituinte da cultura - que, como para Freud, não se distinguiria da civilização -, cuja força se materializa em uma espécie de "pecado original” (Adorno, 1986a, p. 20; 2001, p. 16), a separação radical entre trabalho intelectual e trabalho corporal. Essa cisão está fundada na repressão pulsional, na relação de amor-ódio pelo corpo e na denegação do desejo, que resultam não em um "ímpeto originário", mas num profundo mal-estar (Horkeimer; Adorno, 1985, p. 218; 1986, p. 267-268).

Nos termos de Adorno, a compreensão orteguiana de que a força criadora humana proviria do luxo vital, do ócio, o qual teria naquela cisão ancestral sua origem, apresenta-se como regressiva. Negar a separação entre trabalho corporal e intelectual, fingindo uma harmoniosa identidade, corresponde a recalcar o sofrimento que dá origem a essa cisão e que dela se origina (Adorno, 1986a, p. 17; 2001, p. 14). Enquanto Ortega y Gasset fala em uma razão imaginadora, que permitiria ao humano conceber projetos extranaturais autênticos, Adorno destaca, especialmente nas suas análises sobre os mecanismos da indústria cultural, a "atrofia da fantasia", bloqueada pela repressão pulsional e pela falsa sublimação (Horkeimer; Adorno, 1985, p. 130; 1986, p. 161).

Outra diferença está na noção de vitalidade, presente, com bastante força, em Ortega. Para Adorno, o que ocorre com o processo de tecnificação que faz esquecer o sofrimento resultante da violência arcaica, constantemente atualizada, contra nossa naturalidade primária, não é o aumento da vitalidade humana, mas exatamente do seu contrário, a reificação. 0 refinamento trazido pelo aparato tecnológico e a instrumentalidade corporal acabariam se convertendo em mediadores da relação de amor-ódio pelo corpo por meio da introversão dos proces-

9. A técnica é uma invenção subordinada a um projeto que é ou deveria ser anterior a um desejo de ser, de tornar-se. Essa procura Ortega denomina “desejo original”. 0 contemporâneo expressaria, no entanto, uma profunda crise de desejos, pois o homem-massa que subiu ao palco da história não sabe o que desejar. 
sos reificadores da tecnificação. O domínio e a manipulação instrumental da natureza, para os quais a técnica é fator constituinte e indispensável, acabam levando inexoravelmente à instrumentalização do humano, assim como a reversão da natureza em matéria bruta conduz não apenas à reificação das relações sociais, mas à conversão, em algo de morto, do que há de mais vital no humano, seu corpo. Para Adorno, com o esclarecimento convertido em seu contrário e com extremamente alto tributo cobrado pela razão autoconservadora, não há qualquer vitalidade em expansão, tampouco um desejo superior que alimentaria o afã humano por felicidade ou bem-estar:

todo esclarecimento burguês está de acordo na exigência de sobriedade, realismo, avaliação correta de relações de força. 0 desejo não deve ser pai do pensamento. [...] a dignidade de herói só é conquistada humilhando a ânsia de uma felicidade total, universal, indivisa. (Horkeimer; Adorno, 1985, p. 62-63; 1986, p. 75-76).

\section{Da crítica à técnica, ou distúrbios que prejudicam seu pleno desenvolvimento}

Atreladas ao problema da relação entre técnica e natureza, emergem as críticas que tanto Adorno quanto Ortega endereçam aos rumos do progresso e do desenvolvimento tecnológico. A crítica que Ortega faz à técnica tem, fundamentalmente, caráter externo: ela teria produzido "aberrações" ou saído de sua rota somente num determinado momento histórico, no interior do qual se convertera em fim em si mesma. Como se lê em La rebelión de las masas (Ortega y Gasset, 1983d, p. 111-310), o problema que se observa a partir dos primeiros anos do século XX está vinculado à existência de uma superabundância de meios, fruto do próprio desenvolvimento da técnica em seu período de maior expansão, o século XIX. Tal excesso, por um lado, bloquearia a consciência dos indivíduos e, por outro, em função da elevação das condições de vida da população europeia, especialmente do "homem-médio", criaria a ilusão de que o futuro estaria garantido, sem que para tanto fossem necessários esforços e sacrifícios em nome da civilização, a "genitora" do progresso. Como decorrência dessa melhoria nas condições de vida, houve uma subida do nível da história, que acabou elevando um "novo" homem ao primeiro plano da vida social e política europeia: o “homem-massa”. De alma vulgar, diferentemente 
dos representantes das elites especiais, ${ }^{\mathbf{1 0}}$ afeitas à vida na civilização, esse homem colocava em perigo o próprio destino não apenas da técnica, que está na base da criação de projetos vitais tanto coletivos quanto individuais, mas da própria civilização que o havia beneficiado com os seus instrumentos, instituições, produtos, etc.

O elitismo aristocrático de Ortega, visível com toda força na obra acima referida, permite-lhe sustentar a ideia de que, em cada cultura ou sociedade, somente uma minoria teria condições de levar a cabo a invenção interna e criativa de um programa extranatural ou mesmo de realizar integralmente esse programa no mundo (Mitcham, 2000, p. 36). O paradoxo, conforme aponta Mitcham (2000), desenha-se da seguinte forma: o crescimento das potencialidades humanas, correspondente ao desenvolvimento atingido pela técnica, ou seja, pelo alargamento da invenção externa, secundária, tende a sobrepujar as potencialidades da invenção interna, os desejos pré-técnicos, dos quais aquela é derivada. "Y esa obnubilación del programa vital traerá consigo una detención o retroceso de la técnica que no sabrá bien a quién, a qué servir." (Ortega y Gasset, 1997, p. 55).

O desenvolvimento da técnica se vê ameaçado pelo comportamento "mimado" e "primitivo" do homem-massa por ela "catapultado" ao primeiro plano da história, ao receber instrumentos para viver intensamente, mas não disciplina e sensibilidade para os "grandes deveres históricos" (Ortega y Gasset, 1983d, p. 173). No entanto, e a despeito das condições pouco favoráveis, Ortega parece não ter dúvidas de que a civilização pode seguir seu rumo e o progresso pode ser retomado. Para tanto, seria preciso que a velha ordem fosse restabelecida e que a sociedade voltasse a ser o que sempre fora: aristocrática (Ortega y Gasset, 1983d, p. 150).

Esse tipo de mentalidade não encontra correspondência em Adorno, cuja crítica mira exatamente o progresso linear e infinito, sem associá-la a qualquer resquício de irracionalidade ou obscurantismo. A recusa de Adorno em dissociar progresso dos meios e progresso da humanidade está vinculada à postura ética derivada do próprio projeto de uma dialética do esclarecimento. Este, destacam Löwy e Varikas (1992, p. 208), não encontra seu destino no grau de desenvolvimento dos conhecimentos, tampouco e nem mesmo em suas promessas prévias, mas na medida em que realiza efetivamente a emancipação. A recusa em dissociar progresso técnico e humano, mas também em confundi-los, revela um fundo duplo

10. Ortega estabelece uma diferenciação da qual emergem duas classes: a dos que são disciplinados, com qualificações especiais e que se enchem de deveres para com a civilização e a cultura - as minorias excepcionais; e a dos que se abandonam a si próprios, medíocres, sem qualificação especial, e que não estão dispostos a realizar esforços para progredir - a maioria, a massa. Às primeiras cabe "pensar" e “mandar”; às segundas, "ouvir” e "obedecer". 
ou um duplo caráter de uma dinâmica que "sempre desenvolveu o potencial da liberdade ao mesmo tempo em que a realidade efetiva da opressão" (Adorno, 1986c, p. 167; 1993, p. 129). No ensaio dedicado a debater as ideias de Veblen, Adorno é ainda mais categórico a respeito dessa imbricação:

Talvez seja permitido formular como uma tese a relação entre progresso - "moderno" - e regressão - "arcaico". Em uma sociedade onde o desenvolvimento e o bloqueio de suas forças são consequências inexoráveis do mesmo princípio, cada progresso técnico significa ao mesmo tempo uma regressão. [...] A barbárie é normal não porque consiste em meros resquícios, mas porque é continuamente produzida na mesma proporção da dominação da natureza. (Adorno, 1986a, p. 85-86; 2001, p. 81-82).

Para Adorno, dois são os momentos fundamentais, embora não os únicos, que revelam a perversa imbricação entre progresso e regressão: a manipulação da consciência coletiva mediada pelos esquemas da indústria cultural, processo no qual o desenvolvimento dos meios de comunicação de massa joga um peso decisivo; a utilização das mais modernas técnicas e dos mais sofisticados experimentos científicos pela barbárie nazista. Antes de serem lidos simplesmente como momentos de "exceção", como má aplicação da ciência e da tecnologia, eles revelariam a existência de um potencial de desumanização nas próprias raízes da técnica e do progresso.

\section{Considerações finais: corpo, técnica e formação}

Não há dúvidas sobre a originalidade da análise que Ortega faz da cultura contemporânea, demarcada, entre outras, pela crítica ao homem-massa. Trata-se da recusa à diluição subjetiva nos ordenamentos do coletivismo manifesto, principalmente, pela banalização e pelo rebaixamento cultural. Essa mescla do homem com a massa, no entanto, só foi possível pela elevação do nível vital que, por sua vez, foi proporcionado por um desenvolvimento da técnica nunca antes visto. Foi a técnica, diz Ortega, que tornou possível a fabricação do mundo em que vivemos, produzindo o que seria supérfluo e, portanto, essencialmente humano, desfrutável por cada um para além das necessidades impostas para a sobrevivência.

A considerar esses aspectos, a posição de Adorno não seria radicalmente diferente da de Ortega, não fosse por duas questões. A primeira delas é o caráter aristocráti- 
co das posições do madrileno, o que o faz considerar a era anterior à burguesa como modelo a ser evocado nos termos de que o etos que lhe corresponde é, exatamente, o da valorização da superfluidade, dos usos das coisas com distinção, um "esforço para economizar esforço" proporcionado pela centralidade da técnica na condição humana.

Não é casual que Ortega tanto valorize o esporte, importante dispositivo pedagógico da educação dos corpos e da sensibilidade aristocráticos, origem prototípica, para ele, da formação do Estado como esfera superior de organização social. Reside nessa busca por um passado que teria sido superior no processo de humanização a crítica que permite a Adorno considerar Ortega como um crítico da cultura, mas de matriz conservadora. Ao propor uma crítica imanente ao tempo presente em seu desenvolvimento contraditório, Adorno não pode recorrer ao passado, a não ser de forma irônica, como faz em suas Minima Moralia (Adorno, 1986c; 1993), sugerindo que na sociedade aristocrática pelo menos ainda havia alguma experiência de autonomia no sujeito, ao contrário do que acontece em uma sociedade administrada e regida pelos esquemas da indústria cultural. A mesma ironia se encontra no elogio do fair-play, parte do ideal educativo do esporte aristocrático, lembrado por Adorno mais de uma vez ao longo de sua obra. Essa recordação não significa saudosismo, nem elogio ao privilégio do aristocrata, mas a aposta histórica de que algo distinto do que hoje vivemos é possível. Esse processo só é viável, nos termos da tradição dialética, não por uma volta conservadora ao passado, nem pela recusa peremptória, mas pela negação enfática do presente.

A crítica de Adorno estende-se sobre si mesma, nos termos de uma dialética do esclarecimento no interior da qual se encontra o tema da técnica. Coloca-se, então, a segunda objeção a Ortega. Para Adorno, há uma dialética da técnica que a vê não apenas como produtora do mundo que artificialmente construímos para nosso bem-viver, como propõe Ortega, mas também como potencial de dominação sob os auspícios da razão instrumental. É no plano da história em seu desenvolvimento, também como barbárie, que a técnica será analisada por Adorno, o que lhe permite dizer que o esporte, para retomarmos um tema caro a Ortega, com ela guarda grande afinidade: as práticas esportivas são possibilidade de reconhecimento dos limites do corpo e do respeito a si e ao outro, mas, também, prática de dilaceração racionalmente mediada desse mesmo corpo, ao transformá-lo em mero instrumento de rendimento cego. Crítica dialética do presente é o que ainda hoje inspira o pensamento de Adorno. 


\section{Referências bibliográficas}

ADORNO, Theodor W. Dialética negativa. Rio de Janeiro: Zahar, 2009.

ADORNO, Theodor W. Educação e emancipação. 2. ed. Rio de Janeiro: Paz e Terra, 2000.

ADORNO, Theodor W. Kulturkritik und Gesellschaft I; Prismen; Ohne Leitbild. Frankfurt: Suhrkamp, 1986a.

ADORNO, Theodor W. Kulturkritik und Gesellschaft I/; Eingriffe; Stichworte. Frankfurt: Suhrkamp, 1986b.

ADORNO, Theodor W. Minima Moralia: reflexões a partir da vida danificada. 2. ed. São Paulo: Ática, 1993.

ADORNO, Theodor W. Minima Moralia. Reflexionen aus dem beschädigten Leben. Frankfurt: Suhrkamp, 1986c.

ADORNO, Theodor W. Negative Dialetik; Jargon der Eigentlichkeit. Frankfurt: Suhrkamp, $1986 \mathrm{~d}$.

ADORNO, Theodor W. Noten zur Literatur. Frankfurt: Suhrkamp, $1986 \mathrm{e}$.

ADORNO, Theodor W. Palavras e sinais. Petrópolis: Vozes, 1995.

ADORNO, Theodor W. Prismas. São Paulo: Ática, 2001.

ADORNO, Theodor W. Vermischte Schriften I. Frankfurt: Suhrkamp, $1986 f$.

HORKHEIMER, Max. Eclipse da razão. São Paulo: Centauro, 2000.

HORKHEIMER, Max; ADORNO, Theodor W. Dialética do Esclarecimento. Rio de Janeiro: Zahar, 1985.

HORKHEIMER, Max; ADORNO, Theodor W. Dialetik der Aufklärung. Frankfurt: Suhrkamp, 1986.

INSTITUTFÜR SOZIALFORSCUNG (Org.). Soziologische Exkurse. Frankfurt: Europäische Verlagsanstalt, 1968.

LÖWY, Michael; VARIKAS, Eleni. A crítica do progresso em Adorno. Lua Nova, São Paulo, n. 27, p. 201-215, dez. 1992.

MITCHAM, Carl. La Transformación tecnológica de la cultura y las crisis de los deseos. Revista de Occidente, Madrid, n. 228, p. 33-52, maio 2000.

ORTEGA Y GASSET, José. A rebelião das massas. 2. ed. São Paulo: Martins Fontes, 2002. 
ORTEGA Y GASSET, José. Meditacion de la técnica y otros ensayos sobre ciencia y filosofia. Madrí: Revista de Occidente en Alianza Editorial, 1997.

ORTEGA Y GASSET, José. Obras completas. Madri: Alianza Editorial; Revista de Occidente, 1983a. (12 Tomos).

ORTEGA Y GASSET, José. Obras completas - Tomo I. Madri: Alianza Editorial; Revista de Occidente, $1983 \mathrm{~b}$.

ORTEGA Y GASSET, José. Obras completas - Tomo II. Madri: Alianza Editorial; Revista de Occidente, $1983 \mathrm{C}$.

ORTEGA Y GASSET, José. Obras completas - Tomo IV. Madri: Alianza Editorial; Revista de Occidente, $1983 \mathrm{~d}$.

ORTEGA Y GASSET, José. Obras completas - Tomo VII. Madri: Alianza Editorial; Revista de Occidente, $1983 e$.

ORTEGA Y GASSET, José. Obras completas - Tomo IX. Madri: Alianza Editorial; Revista de Occidente, $1983 \mathrm{f}$.

RUBIO, Luciano Espinosa. Razón, naturaleza y técnica en Ortega y la Escuela de Frankfurt. Isegoría, Madrí, n. 21, p. 101-129, 1999.

Submetido à avaliação em 30 de julho de 2013.

Aprovado para publicação em 11 de outubro de 2013. 